\title{
Programa de Competências Pessoais e Sociais para adultos em exclusão social
}

\author{
Personal and Social Program Skills for adults in social exclusion
}

\author{
Hélder Rêgo Fernandes*, Elisa Moreno**, Suzana Nunes Caldeira***, Célia Barreto Carvalho**** \\ *Associação Novo Dia, **Universidade dos Açores, ***Universidade dos Açores - CICS.NOVA.UAçores, ****Universidade dos \\ Açores - CINEICC
}

\section{Resumen}

Este trabalho apresenta um programa de promoção de competências pessoais e sociais para públicos em situação de exclusão social, designado "Saber, Pensar e Agir SPA". Constituído por 12 sessões e estruturado em três áreas, comunicação e relações interpessoais, gestão doméstica e comportamentos de riscos/saudáveis, contou, na sua 1. ${ }^{\mathrm{a}}$ edição, com 8 adultos com multiproblemáticas associadas. Dos resultados obtidos, através de grelhas de observação e registos de comportamento, constatou-se a importância da continuidade de ações desta natureza, não só pelo conhecimento e reeducação de comportamentos mas também pelo reforço de laços afetivos e potencialização de atitudes de cooperação e interajuda.

Palavras-chave: população em risco, competências sociais, gestão doméstica, comportamentos de risco, comportamentos saudáveis.

\begin{abstract}
This paper presents "Saber, Pensar e Agir- SPA" a Personal and Social Program Skills for adults in social exclusion. The program comprised 12 sessions and it was structured into three areas, communication and interpersonal skills, household management, and risk and healthy behaviors. The $1^{\text {st }}$ implementation of the program included 8 participants 7 women and 1 man with multiple problems. The results obtained through observation grids and behavior records shows the importance of continuing promote this kind of programs, not only for knowledge and rehabilitation of behaviors but also strengthening emotional ties and enhancing cooperation and self-help attitudes.
\end{abstract}

Keywords: risk population, social skills, household management, risk behavior, health behavior

\section{Introdução}

O fenómeno de pobreza e exclusão social, caraterizado como um processo de rutura do indivíduo com a sociedade, é uma realidade a que a ilha de S. Miguel Açores, em Portugal, tem assistido, quer por fatores de ordem económica, quer sociais e/ou culturais.

De acordo com dados facultados pelo Instituto Nacional de Estatística (2012) os Açores são a região do País com maiores taxas de desigualdades sociais e pobreza, situando-se nos $17,9 \%$ no ano de 2010/2011, correspondendo a três pontos percentuais acima da média nacional.

Como forma de dar resposta e suporte aos grupos mais vulneráveis em termos de risco psicossocial, nos Açores várias Instituições Particulares de Solidariedade Social (IPSS) têm procurado atuar sobre necessidades específicas identificadas. É o caso da Novo Dia Associação para Inclusão Social, sedeada em Ponta Delgada, que intervém junto de homens e mulheres em situação extrema de exclusão social: deportados, ex-reclusos, sem-abrigos, toxicodependentes, prostitutos (as), e mulheres e jovens em situação de violência doméstica o e/ou com medidas de proteção judicial.

A Novo Dia, para além do desenvolvimento e implementação de estruturas físicas destinadas a pernoita, higiene e alimentação dos seus utentes, tem desenvolvido um trabalho de articulação com entidades parceiras e a comunidade em geral com vista à facilitação da inclusão social daqueles. Todavia, atendendo à conjuntura atual do País e, simultaneamente, à baixa instrução e qualificação profissional dos indivíduos que recorrem à Associação, fator acentuado por dificuldades de adaptação, falta de motivação, baixa tolerância à frustração, baixa autoestima, dificuldades comunicacionais e relacionais (e.g., Bento \& Barreto, 2002), as oportunidades de inserção psicossocial ficam muito dificultadas.

Como dizem Rijo e colaboradores (2004, p. 6), nesta área de intervenção "os indivíduos mais desajustados possuem défices de competências sociais que os prejudicam no seu funcionamento e adaptação social, no estabelecimento de relações saudáveis, inserção no meio, valorização social, etc."

De acordo Del Prette e Del Prette (2011) a competência social é entendida como a capacidade do indivíduo organizar pensamentos, sentimentos e comportamentos de acordo com os seus objetivos pessoais, procurando articular e adaptar-se as instâncias provenientes do ambiente, a partir do qual obtém resultados positivos, fruto da relação com os outros.

$\mathrm{Na}$ literatura encontramos estudos (e.g.; Wagner, Silva, Zanettelo, Margareth \& Oliveira, 2011; Del Prette \& Del Prette, 2011) que apontam para a importância da promoção de competências sociais por estas se revestirem de um caráter protetor de comportamentos desajustados e disfuncionais em diferentes faixas etárias e nos mais diversos contextos (Murta, 2005).

Por exemplo, Matos, Simões e Canha (2012), num estudo que realizaram junto de jovens com perturbações 
do comportamento, aplicaram um programa de promoção de competências sociais focado, essencialmente, resolução de problemas e treino da assertividade. O programa foi constituído por 23 sessões e contou com a participação de 13 rapazes entre os 14 e 16 anos de idade, com comportamentos desviantes. Dos resultados obtidos, os autores constataram uma diminuição do comportamento agressivo e da impulsividade, maior capacidade para resolver problemas, maior capacidade de autocontrolo e crenças mais esbatidas relativamente à legitimidade das agressões.

Murta (2005) sintetiza um outro estudo de Vila, Silveira e Gongora (2003), o qual consistiu numa intervenção com adultos com comportamentos disfuncionais, em contexto clínico. A intervenção foi constituída por 4 sessões individuais de preparação para inserção dos participantes no grupo, 12 sessões intergrupais focadas promoção de competências pessoais e sociais, 4 atendimentos realizados quinzenalmente e 2 telefonemas para verificação da manutenção dos comportamentos. Das sessões em grupo, foram abordados temas como direitos humanos, discriminação das diferenças entre assertividade, agressividade e passividade; e estabelecimento de conversações. Dos resultados obtidos, os autores (2003), observaram um aumento de assertividade e empatia e uma maior facilidade, por parte dos participantes, na discriminação das causas das suas próprias dificuldades interpessoais.

Mais recentemente, Liu e colaboradores (2013) procuraram verificar melhorarias nas competências sociais e emocionais em indivíduos com autismo e défices intelectuais, por intermédio de um programa de formação num local de trabalho. O programa, com duração de 6 meses, 5 dias na semana e 6 horas/dia, contou 14 adultos com autismo e deficiência intelectual leve a moderada, dos quais 10 eram do sexo masculino. Os resultados indicaram que os participantes obtiveram melhorias em comportamentos importantes no contexto laboral, demostrando trabalho em equipa, solicitando informações ao supervisor quando necessário e respondendo às instruções que lhe eram dadas. Indicaram, também, um aumento na capacidade de comunicação e nas interações sociais estabelecidas. Foi observado, ainda, que os participantes demostraram estar menos confusos e deprimidos e com autoconceito fortalecido após a frequência de sessões de controlo emocional.

Sendo assim, os estudos acima descritos parecem ir ao encontro de Del Prette e Del Prette (2011, p.20), quando dizem que os programas de promoção de competências sociais, ao contemplarem um conjunto de atividades planeadas e orientadas por um formador, contribuem para "ampliar a frequência e/ou melhorar a proficiência de habilidades sociais já aprendidas, mas deficitárias; ensinar habilidades sociais novas significativas; e diminuir ou extinguir comportamentos concorrentes com tais habilidades".

Neste enquadramento, e tendo em atenção os défices pessoais e sociais apresentados pelos clientes da Novo Dia, considerou-se vantajosa a elaboração e implementação de um programa desta natureza, com conteúdos e metodologia adaptados às especificidades do público-alvo, na tentativa de se promover comportamentos pró-sociais e reduzir problemas comportamentais e relacionais.

\section{Método}

\section{Participantes}

Iniciaram o programa 8 adultos, 7 do sexo feminino e 1 do sexo masculino, com idades compreendidas entre os 23 e 43 anos, dos quais 5 estavam acolhidos na Associação Novo Dia e 3 residir quartos comparticipados pelo Instituto de Segurança Social dos Açores. Os participantes possuíam baixa escolaridade e antecedentes de dependência de álcool e outras substâncias (e.g., heroína e cocaína), práticas de prostituição, violência doméstica, deportação e perturbações da personalidade, humor e ansiedade. Importa referir que 3 elementos não concluíram o programa, quer por faltas variadas associadas a instabilidade psicológica, quer por abandono da instituição. Assim, o programa foi frequentado na íntegra por 5 elementos.

\section{Materiais e Instrumentos}

A avaliação do progresso dos participantes foi efectuada a partir de técnicas observacionais, mais propriamente através de grelhas de observação e anotações/registo do comportamento dos clientes.

Relativamente à grelha de observação, os indicadores tomados foram: assiduidade às sessões; relações interpessoais (relação com o grupo de pares e formador); intervenções orais; interesse e participação nas atividades de grupo. A modalidade de registo para cada indicador foi de 1 a 5 , sendo que pontuações mais elevado traduzem mais prestação do participante na sessão.

Relativamente às anotações/registo do comportamento dos clientes, foram efectuados de modo livre, sempre que se entendeu oportuno e relevante.

\section{Procedimentos}

Inicialmente realizou-se um levantamento de necessidades na Associação através de observação direta, análise documental e auscultação do pessoal técnico. Os elementos colhidos, conjugados com conhecimento provindo da literatura científica, impulsionaram a elaboração e realização de um programa de promoção e robustecimento de competências de autonomização para os clientes da instituição, que foi designado por Saber-Pensar-Agir (SPA). Após a conceção do programa, procedeu-se à divulgação do mesmo junto dos técnicos da instituição e clientes. Seguiu-se a fase de recrutamento, selecção e inscrição dos clientes no programa.

O SPA, nesta primeira aplicação, decorreu entre Outubro e Dezembro de 2014. É constituído por 12 sessões, de aproximadamente 90 minutos cada, e organizado em três áreas: Comunicação e Relações 
Interpessoais, apostada na promoção do reportório de habilidades sociais e na redução de comportamentos disfuncionais e inadaptados; Gestão Doméstica, incidindo na organização de gastos económicos para maior facilidade em viver autonomamente; e Comportamento de Risco e Saudáveis, incidindo na consciencialização dos riscos efetivos associados aos comportamentos de risco (e.g., consumo de substâncias psicoativas, sexo desprotegido) e na vantagem da adoção de comportamentos saudáveis e/ou estratégias que minimizem os riscos ou fomentem redução de danos.

Cada sessão do SPA, exceto a primeira, foi estruturada em três momentos: (1) momento inicial, espaço para relembrar, rever e partilhar episódios que possam ter decorrido desde a sessão anterior relacionados com conteúdos já abordados; (2) momento intermédio, destinado ao desenvolvimento do tema específico da sessão, recorrendo a role-plays, discussão em grupo e visualização de vídeos; (3) momento final, destinado à síntese da sessão e ao incentivo à adoção de práticas quotidianas em conformidade com o tópico central da sessão.

Em todas as sessões foi efetuado o registo de avaliação do progresso de cada um dos participantes na grelha de observação. Este registo foi complementado com anotações escritas, correspondendo a observações do dinamizador ou a narrativas dos participantes, sempre que se entendeu útil em termos de facilitar a compreensão/interpretação do registo quantitativo.

\section{Resultados}

No quadro 1 apresentam-se os resultados relativos aos indicadores avaliados ao longo do programa, por área: I Comunicação e Relações Interpessoais; II - Gestão Doméstica; III - Comportamentos de Risco/Saudáveis. Apesar de se trabalhar com 5 participantes, optou-se por apresentar a média dos seus resultados nas 12 sessões. Lembra-se que os valores se situam entre 1 e 5 , sendo este último valor considerado o mais favorável/bem-sucedido.

Quadro 1. Média dos indicadores de desempenho dos participantes, por áreas temáticas e na totalidade do programa

\begin{tabular}{lcccc}
\hline \multicolumn{1}{c}{ Indicadores } & Área & Área & Área & \multirow{2}{*}{ Total } \\
& I & II & III & \\
\hline Assiduidade às sessões & 4.1 & 4.4 & 4.5 & 4.3 \\
Relações interpessoais & 4.0 & 4.0 & 4.2 & 4.1 \\
Intervenções orais & 4.0 & 4.2 & 4.0 & 4.1 \\
Interesse e participação & 4.1 & 4.4 & 4.2 & 4.2 \\
nas atividades & 4.1 & 4.3 & 4.2 & 4.2 \\
Total & & & \\
\hline
\end{tabular}

Observa-se no quadro 1 que as médias obtidas nos diferentes indicadores expressam elevada prestação dos participantes em cada um dos módulos/Áreas e no total do SPA. Os participantes foram assíduos, relacionam-se positivamente com os restantes colegas e formador, adotaram um papel ativo nas sessões, participando e demostrando interesse pelos conteúdos abordados. Para além disso, constata-se uma ligeira evolução, ao longo do programa nos itens assiduidade e relações interpessoais. Em termos de Áreas, a Gestão Doméstica surge em primeira posição.

Em temos dos registos escritos, apresenta-se uma parcela muito reduzida do material colectado, tendo em conta cada uma das áreas trabalhadas. Primeiro oferecem-se exemplos de discursos dos participantes aquando da exploração da Comunicação e Relações Interpessoais, depois passa-se a anotações feitas pelo dinamizador quando se realizaram actividades na Área da Gestão Doméstica e, por fim apresentam-se impressões/inferências do dinamizador referentes à Área Comportamentos de Risco/Saudáveis. A apresentação das descrições é precedida pela contextualização no âmbito do tema da sessão.

\section{Área I - comunicação e relações interpessoais.}

$\mathrm{Na}$ Área da Comunicação e Relações Interpessoais partilham-se discursos dos participantes colhidos na sessão 6. Esta sessão visa mostrar que existe um estilo de comportamento funcional, nomeadamente sensibilizar para o comportamento assertivo e a resolução assertiva de conflitos (reais e hipotéticos). O trabalho é realizado através da técnica de roleplay em dois momentos intermediados com exposição oral. Assim, há um primeiro roleplay antes de se abordar a temática estilos comunicacionais e comportamentos de assertividade, e um segundo roleplay após abordagem ao tema. Os excertos dos discursos dos participantes, que se apresentam no Quadro 2, reportam-se ao momento 1 do roleplay e a uma situação em que Sujeito A utilizou, por breves instantes, material do sujeito B sem autorização deste.

Quadro 2. Discurso proferido pelos participantes na realização do roleplay, antes da apresentação dos estilos comunicacionais

\begin{tabular}{|c|c|}
\hline Diálogo entre A1 e B1 & Diálogo entre A2 e B2 \\
\hline $\begin{array}{l}\text { B1 - "Tu nunca mais mexes } \\
\text { nas minhas coisas senão } \\
\text { parto-te um dedo" }\end{array}$ & $\begin{array}{l}\text { B2 - "Eu não quero saber! } \\
\text { Quando te vir, outra vez, a } \\
\text { mexer nas minhas coisas } \\
\text { nem sabes o que te faço" }\end{array}$ \\
\hline $\begin{array}{l}\text { A1 - "Por é que tas falar a } \\
\text { assim? Achas que tenho medo } \\
\text { de ti?" }\end{array}$ & $\begin{array}{l}\text { A2 - "Quando és tu nunca } \\
\text { há problema agora que sou } \\
\text { eu! Nem fales comigo!" }\end{array}$ \\
\hline
\end{tabular}

As verbalizações inscritas no Quadro 2 eram acompanhadas por tom de voz alto, gestos intimidatórios e ameaçadores (e.g., apontar o dedo, cabeça e peito erguido sobre o outro), olhar fixo do emissor, desviando olhar quando o outro respondia, sobreposição no diálogo. Em suma, um estilo comportamental do tipo agressivo.

No Quadro 3 apresenta-se o momento 2 do roleplay, isto é, após a exploração do tema e a instrução do dinamizador para recurso ao comportamento assertivo. 
Quadro 3. Discurso proferido pelos participantes na realização do roleplay, com instrução de recurso ao comportamento assertivo

\begin{tabular}{|c|c|}
\hline Diálogo entre A1 e B1 & Diálogo entre A2 e B2 \\
\hline $\begin{array}{l}\text { B1 - "Porque mexeste nas } \\
\text { minhas coisas? Tasse bem! } \\
\text { (risos) }\end{array}$ & $\begin{array}{l}\text { B2 - Mexeste nas minhas } \\
\text { coisas? Para a próxima, tens } \\
\text { que pedir? }\end{array}$ \\
\hline $\begin{array}{l}\text { A1 - "Está bem... Para a } \\
\text { próxima aviso" (riso e não faz } \\
\text { mais comentários). }\end{array}$ & $\begin{array}{l}\text { A2 - Mas eu pedi-te tu é } \\
\text { que não ouviste, mas tens } \\
\text { razão! }\end{array}$ \\
\hline
\end{tabular}

A partir do quadro 2, observa-se que o diálogo decorrido entre A1 e B1, carece de expressividade e defesa dos interesses do próprio, numa eventual tentativa de amenizar a situação. Já na realização do roleplay com os participantes $\mathrm{A} 2$ e $\mathrm{B} 2$ há maior aproximação ao estilo assertivo. No entanto, em ambos os casos, as verbalizações não são congruentes com o comportamento observado. O participante A2 mantém um tom de voz intimidatório, olhar inquisidor e gesticulação exacerbada; o participante A1 evita o conflito, consentindo com o que é dito sem prolongar o diálogo para se justificar.

\section{Área II - gestão doméstica.}

Para ilustrar uma situação da Área da Gestão Doméstica seleccionou-se a sessão 10, que tem como objetivos falar sobre gastos económicos do quotidiano; distinguir gastos essenciais e acessórios; contatar com estratégias úteis para melhorar a gestão financeira, efetuar uma simulação de ida ao supermercado, selecionando livremente bens a adquirir. Tal como no caso anterior, esta sessão comporta dois momentos de protagonização mais ativa dos participantes, o primeiro antes de se abordar o tema e o segundo após se explorar a temática e facultar ferramentas úteis à gestão financeira. No quadro 4, é apresentado o registo observado pelo formador nos $1 .^{\circ} \mathrm{e} 2 .^{\circ}$ momentos.

Quadro 4. Anotações registadas, em dois momentos, da simulação de compras num supermercado

\begin{tabular}{|c|c|}
\hline $\begin{array}{c}\text { Observações registada } \\
1 .{ }^{\circ} \text { momento }\end{array}$ & $\begin{array}{c}\text { Observações registada } \\
2 .^{\circ} \text { momento }\end{array}$ \\
\hline $\begin{array}{l}\text { Os participantes circulam } \\
\text { pelo supermercado (sala) sem } \\
\text { previamente pensarem e } \\
\text { realizarem uma lista dos } \\
\text { produtos a comprar. Na } \\
\text { compra dos géneros, não têm } \\
\text { em conta a marcas brancas } \\
\text { e/ou mais baratas. Dois deles } \\
\text { optam por produtos } \\
\text { pré-cozidos (mais caros). } \\
\text { Além disso, todos os } \\
\text { participantes, adquirem } \\
\text { produtos não essenciais, } \\
\text { como café e bolachas. }\end{array}$ & $\begin{array}{l}\text { Os participantes realizam } \\
\text { uma lista de compras e em } \\
\text { seguida, iniciam as } \\
\text { compras. Há procura do } \\
\text { mesmo produto de marca } \\
\text { mais barata. Há procura de } \\
\text { produtos essenciais à } \\
\text { confeção de refeições (invés } \\
\text { dos pré-cozidos). } \\
\text { Observa-se maior calma e } \\
\text { organização na realização } \\
\text { das compras. À medida que } \\
\text { encontram os produtos os } \\
\text { participantes assinalam na } \\
\text { lista. }\end{array}$ \\
\hline
\end{tabular}

Como pode ser observado no quadro 4 , os participantes do $1 .^{\circ}$ para o $2 .^{\circ}$ momento, na escolha dos alimentos, recorreram a estratégias úteis para economizar tempo e dinheiro. Enquanto no $1 .^{\circ}$ momento apresentam alguma impulsividade, sem considerar o valor dos produtos comprados, no segundo $2 .^{\circ}$ momento as compras eram efetuadas com ponderação, com recurso a uma lista decompras, e à seleção dos produtos com base no preço/ qualidade/marca. Para além dos comportamentos observados, os participantes proferiram vários comentários favoráveis após tomarem contato com os conteúdos, salientando a pertinência atribuída aos de recursos facultados (lista de compras pré-definida) e a utilidade das estratégias de poupança (caderneta de despesas, semanais e mensais em diferentes áreas, como despesas de rendas, alimentação, saúde, educação). Apresenta-se um comentário do participante 3 , como exemplo:

"Esse livro dá jeito! Assim, dá para vermos onde gastamos e podemos poupar mais dinheiro". E ainda, "Não me apercebia que bebendo a quantidade de café que bebo, no final do mês gastava 30 euros. Isso é muito dinheiro!" (ar muito surpreendido).

\section{Área III - comportamentos de risco/Saudáveis.}

Finalmente, para concretizar melhor a Área Comportamentos de Risco/Saudáveis, materializada, sobretudo, nas sessões 11 e 12, no Quadro 5 apresenta-se uma síntese de descrições/inferências do dinamizador realizadas a partir dos registos efetuados por aquele ao longo das sessões. Nestas sessões pretende-se que os participantes discutam implicações dos comportamentos de risco e vantagens da minimização do risco. As estratégias adotadas para o efeito assentam na visualização de vídeos e discussão de grupos.

Quadro 4. Anotações registadas acerca do tema explorado ao longo das sessões 11 e 12.

\begin{tabular}{|c|c|}
\hline Tema explorado & Síntese das anotações da sessão \\
\hline $\begin{array}{c}\text { Doenças } \\
\text { Sexualmente } \\
\text { transmissíveis }\end{array}$ & $\begin{array}{l}\text { Os participantes reconhecem a } \\
\text { importância uso do preservativo como } \\
\text { método contracetivo útil na prevenção de } \\
\text { DST's. No entanto, verbalizam que a } \\
\text { transmissão das DST's só acontece se } \\
\text { ocorrer penetração no ato sexual. } \\
\text { Identificam hepatite B e VIH. Dizem não } \\
\text { conhecer a sífilis, a herpes genital e a } \\
\text { gonorreia. Apesar de mencionarem a } \\
\text { hepatite B e VIH, mostram conhecimento } \\
\text { limitado sobre a sua forma de contágio. }\end{array}$ \\
\hline
\end{tabular}

Os participantes reconhecem o tabaco como prejudicial para a saúde. No entanto, associam o seu consumo apenas ao cancro do pulmão. Os participantes reconhecem o álcool como prejudicial para a saúde. Enquanto consequência física, falam em problemas do fígado Consumos de (cirrose). Imputam o consumo de álcool a substâncias problemas familiares, amorosos, Psicoativas financeiros e laborais.

Quando às substâncias psicoativas ilícitas, todos os participantes identificaram a cannabis, o haxixe, a heroína e a cocaína. Todavia, a maioria verbalizou desconhecer efeitos prejudicais relativamente às duas primeiras, e apenas 2 identificaram efeitos e consequências físicas e psicológicas das restantes (ex-consumidores). 
Através do ilustrado no Quadro 5, observa-se que os participantes tendem a desconhecer algumas das consequências físicas e psicológicas subjacentes à prática de relações sexuais desprotegidas e a consumos de substâncias aditivas/psicoativas.

$\mathrm{Na}$ abordagem às substâncias psicoativas, o testemunho de dois participantes com antecedentes de consumos aditivos revelou ser muito importante, pois permitiu aos restantes tomarem contato com descrições decorrentes de vivências relatadas na primeira pessoa. Refira-se ainda, que a partilha desses testemunhos terá criado a oportunidade para que um dos participantes reconhecesse o problema de consumo com que se confrontava e que até então nunca tinha assumido.

\section{Discussão}

Os resultados do presente estudo evidenciam a importância e necessidade de se continuar a apostar em intervenções desta natureza com este púbico, contribuindo assim para o processo de autonomização e de reinserção social.

Constata-se que os participantes, ainda que reconheçam e diferenciem respostas comportamentais assertivas, as suas dificuldades passam pela sua atuação em conformidade. $\mathrm{O}$ que nos revela que a promoção de competências sociais, mais precisamente da assertividade, é um aspeto emergente neste público. Bandeira, Machado e Pereira (2002, p.111) afirmam que "um melhor desempenho assertivo dos pacientes contribuiria para uma maior capacidade de enfrentamento de situações de conflito interpessoal, o que resultaria em menor nível de estresse, aumentando consequentemente a qualidade de vida das pessoas".

Abordando questões inerente à área Gestão Doméstica observou-se mudanças positivas nas atitudes/ comportamentos dos participantes, mostrando refletir sobre gastos económicos e identificando e distinguindo os bens essenciais dos acessórios, recorrendo a estratégias de poupança, como o uso da caderneta. Deste modo, espera-se que a continuada anotações dos gastos, seja um indicador da manutenção da gestão de gastos financeiros, permitindo maior consciência das suas finanças.

Quanto à Área Comportamentos de Risco constatou-se um maior esclarecimento e conhecimento dos participantes relativamente as informações partilhadas e discutidas, informações que assumem um papel fundamental da mudança de atitudes e comportamentos. Esta observação vai ao encontro de Bastos (2005) quando menciona que indivíduos com maior conhecimento acerca das doenças infeciosas têm uma atitude mais favorável em relação ao sexo protegido e à utilização de boas práticas no consumo de substâncias psicotrópicas injetáveis. Para além disso, a promoção de comportamento saudável, demonstrou grande pertinência no grupo, visto que o conhecimento acerca da utilização do preservativo é redutor. Não é suficiente ter consciência do uso do preservativo, é necessário saber utilizá-lo corretamente para que possa atuar preventivamente contra DST's. Como afirma Bastos (2005) "muitas pessoas o usam incorrectamente, aplicando-o já depois de contato em órgãos genitais e por vez após troca de fluidos pré-ejaculatórios" (Basto 2005). Assim, apostar na prevenção minimização de comportamentos de risco assume-se como uma prioridade.

A finalizar diríamos que o processo decorrido e os resultados alcançados, ainda que estes últimos sejam apenas indicativos, são estimulantes à prossecução de novas edições do SPA. Neste sentido, está a ser desenhada uma segunda edição, introduzindo ajustamentos decorrentes desta primeira experiência.

\section{Referências}

Bandeira, M.; Machado, E.; \& Pereira, E. (2002). Reinserção Social de Psicóticos: Componentes Verbais e Não-Verbais do Comportamento Assertivo, em Situações de Fazer e Receber Críticas. Psicologia: Reflexão e Crítica, 15(1), 89-104

Bastos, J. (2005). VIH/Sida e toxicodependências: mais vale prevenir. Revista Toxicodependências 11(2), 75-81

Bento, A. \& Barreto, E (2002). Sem - Abrigo, Sem-Amor. Lisboa: Climepsi Editores

Instituto Nacional de Estatística (2012). Inquérito às Despesas das Famílias 2010/2011. Lisboa. ISSN 1647-0443

Liu, k. Wong, d.; Chung, a. Kwok, N.; Lam, M.; Yuen, C.; Arblaster, K.; \& Kwan, A. (2013). Effectiveness of a Workplace Training Programme in Improving Social, Communication and Emotional Skills for Adults with Autism and Intellectual Disability in Hong Kong - A Pilot Study. Occupational Therapy International, 20, 198-204

Matos, M.; Simões, C.; \& Canha, L. (2012). Competência social em adolescentes com problemas de comportamento. Em Matos, M. \& Tomé, G. (orgs.). Aventura Social: Promoção de Competências e do Capital Social para um Empreendedorismo com Saúde na Escola e na Comunidade - Volume 2: Intervenções com jovens e na comunidade ( $1^{\mathrm{a}} \mathrm{ed}$.). Lisboa: Placebo Editora.

Murta, S. (2005). Aplicações do Treinamento em Habilidades Sociais: Análise da Produção Nacional. Psicologia: Reflexão e Critica, Vol. 18 (2), p. 283-291.

Del Prette, A. \& Del Prette, (2011). Habilidades sociais: programas efetivas em grupo. São Paulo: Casa do Psicólogo.

Rijo, D.; Sousa, N. M.; Lopes, J; Pereira, J.; Vasconcelos, J.; Mendonça, C. M.; Silva, J. M.; Ricardo. N \& Massa, S (2004). GPS - Gerar Percursos Sociais: Programa de intervenção e reabilitação para jovens com comportamento social desviante.

Wagner, M.; Garcia, S.; Zanettelo, L; \& Oliveria, M. (2010.). O uso da maconha associado ao deficit de habilidades sociais em adolescente. Revista eletrónica Suade mental Alcool e drogas, 6 (2), 255-273. 